\title{
COOPERATIVE LEARNING DENGAN MODEL TGT (TEAMS GAMES TOURNAMENT) MATERI BILANGAN BULAT BAGI SISWA KELAS IV SEKOLAH DASAR
}

\author{
Endrayana Putut L.E. \\ Jurusan Pendidikan Guru Sekolah Dasar, Fakultas Bahasa dan Sastra, Universitas Wijaya Kusuma \\ endrayanaputut29@gmail.com
}

\begin{abstract}
Abstrak
Matematika merupakan ilmu yang mendasari perkembangan teknologi modern, mempunyai peranan yang penting dalam berbagai disiplin ilmu dan memajukan daya pikir manusia. Perkembangan di bidang teknologi informasi dan komunikasi dipengaruhi dan dilandasi oleh perkembangan Matematika. Matematika merupakan pelajaran yang berkaitan langsung dengan perkembangan ilmu pengetahuan dan teknologi, baik materi maupun kegunaannya. Sehingga Matematika perlu dikembangkan dan ditingkatkan meliputi materi, proses belajar mengajar, lingkungan serta fasilitas sekolah, sebagaimana tujuan khusus pengajaran Matematika di sekolah dasar yaitu menumbuhkembangkan keterampilan berhitung yang berguna dalam kehidupan sehari-hari. Berdasarkan hasil pengamatan saat pembelajaran, masalah yang dihadapi siswa adalah kurangnya penguasaan konsep tentang bilangan bulat sehingga hasil belajar siswa masih kurang. Guru juga masih mendominasi pembelajaran dengan metode ceramah sehingga yang terjadi adalah teacher centered. Hal tersebut menjadikan peserta didik kurang termotivasi dan kurang semangat dalam mengikuti pembelajaran. Untuk itu perlu dilakukan perubahan dalam pembelajaran yaitu dengan model pembelajaran yang menciptakan pembelajaran menjadi students centered. Jadi kegiatan belajar berpusat pada peserta didik, guru sebagai motivator dan fasilitator didalamnya agar suasana kelas lebih kondusif. Teams Games Tournament (TGT) menjadi salah satu model pembelajaran yang dapat diterapkan untuk mengubah paradigma di atas. Hal ini tampak dalam perubahan yang signifikan pada hasil post test siswa dibandingkan hasil pre test.
\end{abstract}

Kata Kunci: kreativitas, pemecahan masalah matematika terbuka, gaya belajar

\begin{abstract}
Mathematics is a science that underlies the development of modern technology, has an important role in various disciplines and advance the human mind. The development in the field of information and communication technology is influenced and based on the development of Mathematics. Mathematics is a lesson that is directly related to the development of science and technology, both material and its usefulness. So Mathematics needs to be developed and upgraded including materials, teaching and learning process, environment as well as school facilities, as the special purpose of teaching Mathematics in primary school is to develop numeracy skills that are useful in everyday life. Based on the results of observations during the learning, the problem faced by students is the lack of mastery of the concept of integers so that student learning outcomes are still lacking. Teachers also still dominate learning by lecturing method so that happened is teacher centered. This makes the learners less motivated and less enthusiastic in following the lesson. For that we need to make changes in learning that is with the model of learning that creates learning to be student centered. So learning activities centered on the learners, teachers as a motivator and facilitator in it so that the atmosphere of the classroom more conducive. Teams Games Tournament (TGT) becomes one of the learning models that can be applied to change the above paradigm. This is evident in significant changes in post test results of students versus pre test results.
\end{abstract}

Keywords: Teams Games Tournament (TGT), cooperative, students centered

\section{PENDAHULUAN}

Matematika merupakan ilmu yang mendasari perkembangan teknologi modern, mempunyai peranan yang penting dalam berbagai disiplin ilmu dan memajukan daya pikir manusia. Perkembangan di bidang teknologi informasi dan komunikasi dipengaruhi dan dilandasi oleh perkembamgan Matematika. Matematika merupakan pelajaran yang berkaitan langsung dengan

perkembangan ilmu pengetahuan dan teknologi, baik materi maupun kegunaannya. Sehingga Matematika perlu dikembangkan dan ditingkatkan meliputi materi, proses belajar mengajar, lingkungan serta fasilitas sekolah, sebagaimana tujuan khusus pengajaran Matematika di sekolah dasar yaitu menumbuhkembangkan keterampilan 
berhitung yang berguna dalam kehidupan sehari-hari. Pengertian Matematika menurut Sumardyono (2004:28) secara umum definisi matematika dapat dideskripsikan sebagai berikut, di antaranya: (1) Matematika sebagai struktur yang terorganisir. Agak berbeda dengan ilmu pengetahuan yang lain, matematika merupakan suatu bangunan struktur yang terorganisir. Sebagai sebuah struktur, ia terdiri atas beberapa komponen, yang meliputi aksioma, pengertian pangkal/primitif, dan dalil/teorema (termasuk di dalamnya lemma (teorema pengantar) dan corolly, (2) Matematika sebagai alat (tool) yaitu matematika juga sering dipandang sebagai alat dalam mencari solusi berbagai masalah dalam kehidupan seharihari, (3) Matematika sebagai pola pikir deduktif yaitu matematika merupakan pengetahuan yang memiliki pola pikir deduktif, artinya suatu teori atau pernyataan dalam matematika dapat diterima kebenarannya apabila telah dibuktikan secara deduktif (umum), (4) Matematika sebagai cara bernalar (the way of thinking) yaitu matematika dapat pula dipandang sebagai cara bernalar, paling tidak karena beberapa hal, seperti matematika memuat cara pembuktian yang sahih (valid), rumusrumus atau aturan yang umum, atau sifat penalaran matematika yang sistematis, (5) Matematika sebagai bahasa artificial artinya simbol merupakan ciri yang paling menonjol dalam matematika. Bahasa matematika adalah bahasa simbol yang bersifat artifisial, yang baru memiliki arti bila dikenakan pada suatu konteks, (5) Matematika sebagai seni yang kreatif yaitu penalaran yang logis dan efisien serta perbendaharaan ide-ide dan pola-pola yang kreatif dan menakjubkan, maka matematika sering pula disebut sebagai seni, khususnya merupakan seni berpikir yang kreatif. Berdasarkan hasil pengamatan saat pembelajaran, masalah yang dihadapi siswa adalah kurangnya penguasaan konsep tentang bilangan bulat sehingga hasil belajar siswa masih kurang. Guru juga masih mendominasi pembelajaran dengan metode ceramah sehingga yang terjadi adalah teacher centered. Hal tersebut menjadikan peserta didik kurang termotivasi dan kurang semangat dalam mengikuti pembelajaran. Untuk itu perlu dilakukan perubahan dalam pembelajaran yaitu dengan model pembelajaran yang menciptakan pembelajaran menjadi students centered. Jadi kegiatan belajar berpusat pada peserta didik, guru sebagai motivator dan fasilitator didalamnya agar suasana kelas lebih kondusif. Menurut Sardiman, belajar itu merupakan perubahan tingkah laku atau penampilan, dengan serangkaian kegiatan misalnya dengan membaca, mengamati, mendengarkan, meniru dan lain sebagainya. Juga belajar itu akan lebih baik, kalau sumber belajar itu mengalami atau melakukannya, jadi tidak bersifat verbalistik. Artz dan Newman mendefinisikan Kooperatif sebagai kelompok kecil atau siswa yang bekerja sama dalam satu tim untuk mengatasi suatu masalah, menyelesaikan sebuah tugas, atau mencapai satu tujuan bersama (Miftahul Huda, 2011). Dari latar belakang di atas, maka perlu dilakukan inovasi baru yaitu pembelajaran dengan metode Tests Games Tournament (TGT) untuk mengubah gaya belajar anak dalam proses pembelajaran agar tujuan pembelajaran dapat tercapai pada siswa kelas IV Sekolah Dasar.

\section{METODE}

Pembelajaran Kooperatif sangat beragam jenisnya. Salah satunya adalah model pembelajaran TGT (Teams Games Tournament). Menurut Suprijono (2012), model pembelajaran TGT merupakan model pembelajaran kooperatif dengan membentuk kelompok-kelompok kecil dalam kelas yang terdiri atas 3-5 siswa yang heterogen, baik dalam hal akademik, jenis kelamin, ras, maupun etnis. Inti dari model ini adalah adanya game dan turnamen akademik. Sebelum memulai game dan turnamen akademik, guru terlebih dahulu menempatkan siswa dalam sebuah tim yang mewakili heterogenitas kelas ditinjau dari jenis kelamin, ras, maupun etnis. Masing-masing siswa nantinya akan mewakili kelompoknya untuk bersaing dalam meja turnamen.

Setelah kelas dibagi menjadi beberapa kelompok kecil, guru kemudian menyajikan materi dan selanjutnya siswa bekerja mengerjakan LKS dalam kelompoknya masing-masing. Apabila ada anggota kelompok yang kurang mengerti dengan materi dan tugas yang diberikan, maka anggota kelompok yang lain bertugas memberikan jawaban seta menjelaskannya sebelum pertanyaan tersebut diajukan kepada guru.

Untuk memastikan apakah semua anggota kelompok telah menguasai materi, maka siswa akan bertanding dalam game dan turnamen ademik. Game hanya diikuti oleh perwakilan dari masing-masing kelompok, sedangkan turnamen diikuti oleh semua siswa.

Ketika turnamen akademik, siswa akan dipisahkan dengan kelompok asalnya untuk ditempatkan dalam meja-meja turnamen. Setiap meja turnamen terdiri dari beberapa siswa yang mewakili kelompoknya masingmasing. Penentuan dimana meja turnamen yang akan ditempati oleh siswa dilakukan oleh guru, yaitu dengan melihat homogenitas akademik. Maksudnya, siswa yang berada dalam satu meja turnamen adalah siswa dengan 
kemampuan akademiknya setara. Hal ini dapat ditentukan berdasarkan nilai yang diperoleh saat pre-test.

Untuk lebih jelasnya, berikut ini disajikan tahapantahapan dalam model pembelaran TGT. Menurut Slavin
(2005:166-167), langkah-langkah model pembelajaran TGT ada lima tahap, yaitu: tahap presentasi di kelas, tim,game, turnamen, dan rekognisi tim.

Tabel 1. Rekognisi Tim

\begin{tabular}{cc}
\hline Kriteria (Rata-rata Tim) & Penghargaan \\
40 & Tim Baik \\
45 & Tim Sangat Baik \\
50 & Tim Super \\
\hline \hline
\end{tabular}

Teknik pengumpulan data yang akan digunakan dalam penelitian ini adalah tes, observasi dan catatan lapangan. Jenis tes yang digunakan dalam penelitian ini adalah tes akhir pembelajaran yaitu evaluasi dengan menggunakan lembar penilaian yang berupa LKS dan

\section{HASIL DAN PEMBAHASAN}

Untuk mengetahui peningkatan hasil belajar siswa, peneliti melakukan penjumlahan nilai yang diperoleh siswa, dibagi dengan jumlah siswa yang ada di kelas. Dirumuskan sebagai berikut:

1. Hasil belajar siswa aspek pengetahuan

$$
\begin{array}{lll} 
& \mathrm{M} & =\frac{\Sigma f x}{N} \\
\text { Keterangan: } & & \\
\mathrm{M} & & \text { Mean } \\
\sum f \mathrm{x} & & =\text { Jumlah } \\
\mathrm{N} & & =\text { Jumla } \\
& &
\end{array}
$$

$$
\begin{aligned}
& =\text { Mean (Nilai rata-rata) } \\
& =\text { Jumlah nilai seluruh siswa } \\
& =\text { Jumlah siswa }
\end{aligned}
$$

$\begin{array}{ll}>80 \% & =\text { Sangat tinggi } \\ 60-79 \% & =\text { Tinggi } \\ 40-59 \% & =\text { Sedang } \\ 20-39 \% & =\text { Rendah } \\ <20 \% & =\text { Sangat rendah }\end{array}$

lembar penilaian individu. Observasi yang dilakukan terhadap aspek keterampilan atau partisipasi aktif siswa selama proses pembelajaran berlangsung serta sikap (afektif) siswa selama proses pembelajaran tersebut.

Ketuntasan belajar siswa secara klasikal digunakan rumus sebagai berikut:

$P=\frac{\sum \text { siswa yang tuntas belajar }}{\sum \text { siswa }} \times 100 \%$

Keterangan:

$\mathrm{P}=$ Presentase ketuntasan belajar

¿siswa yang tuntas belajar $=$ Jumlah frekuensi yang tuntas belajar

$\sum$ siswa $=$ Jumlah seluruh siswa

Dengan kriteria tingkat keberhasilan belajar siswa dalam presentase, yaitu:

$$
\begin{array}{l|l}
>80 \% & =\text { Sangat tinggi } \\
60-79 \% & =\text { Tinggi } \\
40-59 \% & =\text { Sedang } \\
20-39 \% & =\text { Rendah } \\
<20 \% & =\text { Sangat rendah }
\end{array}
$$

\section{Hasil belajar siswa aspek keterampilan}

$$
\text { Nilai Akhir (NA) }=\frac{\text { Skor Perolehan }}{\text { Skor Maksimal }} x \text { Skor Maksimal }
$$

\section{Hasil belajar siswa aspek Afektif}

$$
\text { Nilai Akhir (NA) }=\frac{\text { Skor Perolehan }}{\text { Skor Maksimal }} x \text { Skor Maksimal }
$$

Tabel 2. Konversi Nilai 3 Kompetensi (Pengetahuan, Keterampilan, dan Sikap)

\begin{tabular}{cccc}
\hline Predikat & & Nilai Kompetensi & \\
A & Pengetahuan & Keterampilan & Sikap (Sangat Baik) \\
A- & 4 & 4 & B (Baik) \\
B+ & 3,66 & 3,66 & \\
B & 3,33 & 3,33 & 3 \\
\hline \hline
\end{tabular}




\begin{tabular}{cccc}
\hline Predikat & & Nilai Kompetensi & \\
& Pengetahuan & Keterampilan & Sikap \\
B- & 2,66 & 2,66 & C (Cukup) \\
C+ & 2,33 & 2,33 & \\
C & 2 & 2 & K (Kurang) \\
C- & 1,66 & 1,66 & \\
D+ & 1,33 & 1,33 & 1 \\
D & 1 & Kung \\
\hline \hline
\end{tabular}

\section{PENUTUP}

\section{Simpulan}

Seorang peserta didik dikatakan tuntas belajar untuk menguasai KD pada kurikulum 13 aspek pengetahuan dan KI.4 pada aspek keterampilan. Seorang peserta didik dinyatakan tuntas belajar untuk menguasai KD yang dipelajari apabila menunjukkan indikator nilai $\geq 2.66$ atau berdasarkan hasil tes dihitung dari jumlah siswa menjawab soal benar minimal $80 \%$ dengan mencapai KKM 70. Sedangkan untuk penilaian sikap untuk KD pada KI.1 dan KI.2 berkategori baik. Dari penelitian ini

\section{DAFTAR PUSTAKA}

Arikunto, Suharsimi. (2010). Prosedur Penelitian (suatu pendekatan praktik). Jakarta: PT Rineka Cipta.

Arikunto, A., Suhardjono, \& Supardi. (2008). Penelitian Tindakan Kelas. Jakarta: PT Bumi Aksara.

Aqib, Zainal dkk. (2008). Penelitian Tindakan Kelas.Bandung: Yrama Widya.

Hasbullah. (2008). Dasar-Dasar Ilmu Pendidikan. Jakarta: PT Raja Grafindo Persada.

Huda, M. (2011). Cooperative LearningMetode, Teknik, Struktur dan Model Penerapan. Yogyakarta: Pustaka Pelajar

Indarti, Titik. (2008). Penelitian Tindakan Kelas (PTK) dan Penulisan Ilmiah. Surabaya: FBS UNESA.

Moleong, L.J. (2010). Metode Penelitian Kualitatif Edisi Revisi. Bandung:PT Remaja Rosdakarya.

Nasution. (2008). Berbagai Pendekatan Dalam Proses Belajar \& Mengajar. Jakarta: PT Bumi Aksara

Permendikbud. (2014). Bahasa, Sastra, dan Budi Darma. Surabaya: Temprina Media Grafika

Slavin, R.E. (2005). Cooperative LearningTeori, Riset dan Praktik. Bandung: Nusa Media.

Sugiyono. (2012). Metode Penelitian Kuantitatif Kualitatif dan R\&D. Bandung: CV Alfabeta. terdapat beberapa kesimpulan yaitu model Teams Games Tournament ini dapat digunakan untuk materi bilangan bulat bagi siswa Sekolah Dasar kelas IV. Hal ini ditunjukkan dengan perubahan hasil post test yang signifikan terhadap hasil pre test yaitu tingkat ketuntasan $95 \%$ dari seluruh siswa.

\section{Saran}

Penelitian dilakukan untuk materi pembelajaran yang lainnya dan pada level selain kelas IV ataupun pada jenjang sekolah yang lain, yaitu sekolah menengah.

Sumardyono. (2004). Karakteristik Matematika dan Implementasinya Terhadap Pembelajaran Matematika. Yogyakarta: Depdiknas

Suprijono. (2012). Cooperative Learning Teori dan Aplikasi Paikem. Yogyakarta: Depdiknas. 